\title{
亜音速領域における宇宙往還機の胴体断面形状が 空力特性に及ぼす影響について*1
}

\section{Effect of Fuselage Cross Sections on Aerodynamic Characteristics of Reusable Launch Vehicles in Subsonic Flow}

\author{
只熊憲 治 ${ }^{* 2 * 3}$. 守 田 航 ${ }^{* 2, * 4}$. 麻 生 茂 ${ }^{* 5}$. 谷 泰 寛 ${ }^{* 5}$ \\ Kenji Tadakuma, Wataru Morita, Shigeru Aso and Yasuhiro Tani
}

Key Words : Aerodynamic Characteristics, Fuselage Cross Section, RLV, Subsonic Flow

\begin{abstract}
An experimental study on aerodynamic effect of RLVs (Reusable Launch Vehicles) due to fuselage cross sections has been conducted in subsonic flow. Three fuselage models and two wing-body models have been considered. Fuselage models have a circular, a square and a triangular cross section. Wing-body models have a square and a triangular cross section with wings. Experiments have been conducted under test conditions of free-stream Mach number $M_{\infty}=0.3$ and Reynolds number $R e=3.2 \times 10^{6}$. Aerodynamic forces are measured and flow fields are visualized by smoke-wire technique and oil-flow technique. Results show that fuselage cross sections have much effect on whole aerodynamic characteristics, the fuselage model with a triangular cross section has higher lift coefficient in high angle of attack region than that of the other fuselage models and the wing-body model with a triangular fuselage cross section does not stall till high angle of attack region compared with the "Square" fuselage wing-body model.
\end{abstract}

\section{1. 序論}

宇宙輸送システムは, 宇宙活動における最も基本的な基盤 の 1 つである . 現在 ，完全再使用型宇宙往還機 (Reusable Launch Vehicle , RLV) の開発が進められているが,ささら なるコスト削減，信頼性・安全性の向上が求められている。

再使用型宇宙往還機において, コスト削減, 信頼性・安 全性を向上するためには, 高い空力性能を得ることが重要 課題の 1 つである . 揚力向上は, 着陸速度を遅くし, 着陸 滑走距離を短くすることができ, 帰還候補地か増えること につながる．また，揚抗比向上は，着陸時において，滑走 路へのアプローチを容易にし, 高速時において, クロスレ ンジやダウンレンジを増加させる .

乥こで, 著者らは, 宇宙往還機形状に対し, 高い空力性能 を得るための検討を行った .一般に，再使用型宇宙往還機 は通常の航空機と比較して, 胴体の太さに対して翼が小さ いため，胴体の影響がより大きい．このため再使用型宇宙 往還機に対しても，胴体の断面形状を工夫することによっ て機体全体の空力性能の向上が期待できると考えられる .

過去に，ミサイルの胴体形状が空力特性へ与える影響や， デルタ翼を有する翼胴模型の胴体形状が渦崩壊位置に与え

\footnotetext{
*1 (C) 2007 日本航空宇宙学会

平成 18 年 9 月 29 日原稿受理

*2 九州大学大学院工学府航空宇宙工学専攻

*3 現防衛省航空自衛隊

*4 現 川崎重工業 (株)

$* 5$ 九州大学大学院工学研究院航空宇宙工学部門
}

る影響を調べた例は多数存在する ${ }^{1 \sim 8)}$. しかしながら, 宇宙 往還機のような胴体の影響が大きく，高迎角での飛行も行 う機体に対して，胴体断面形状がどのように空力特性に影 響を与えるかについて調べた研究は著者の知る限りない．

したがって, 本研究では, 胴体の断面形状が空力特性に 及ぼす影響を調べ，产の有効性について検討することを目 的とし，実験を行った．実験は，胴体のみの模型及び翼胴 模型を使用し, 胴体断面形状が全機空力特性に及ぼす影響 を調べた．本論文では，弚れらの実験結果及び考察につい て報告する。

\section{2. 実験装置と方法}

2.1 風洞及び模型 本実験では, 宇宙航空研究開発機 構/宇宙科学研究本部所有の $600 \mathrm{~mm} \times 600 \mathrm{~mm}$ の測定部 を持つ吹きおろし式の遷音速風洞及び九州大学所有の直径 $2 \mathrm{~m}$ の円形断面測定部を持つ回流式低速風洞を用いた .

実験に使用した模型を第 1 图及び第 2 図に示す. 断面形 状の異なる 3 種類の胴体模型を第 1 図に示す . 胴体模型の 断面形状は真円，四角形，二等辺三角形であり，すべて，全 長 $0.3448 \mathrm{~m}$ ，水平投影面積 $1.93 \mathrm{~m}^{2}$ である. これ以降，断 面形状が真円の模型を「真円胴体」，四角形の模型を「四角 胴体」, 二等辺三角形の模型を「三角胴体」と呼ぶことと する．「真円胴体」のノーズ形状は鈍頭オジャイブであり， $\ulcorner$ 四角胴体」,「三角胴体」のノーズ形状は先端に近づくに つれて断面が徐々に円に近づく. 先端部分は 3 つとも半径 $7 \mathrm{~mm}$ の球状になっている.また，空力加熱を考慮した現 


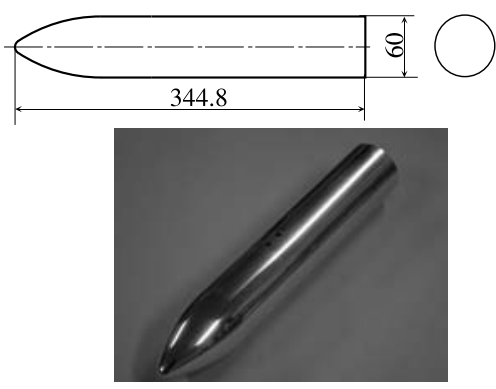

(a) 真円胴体
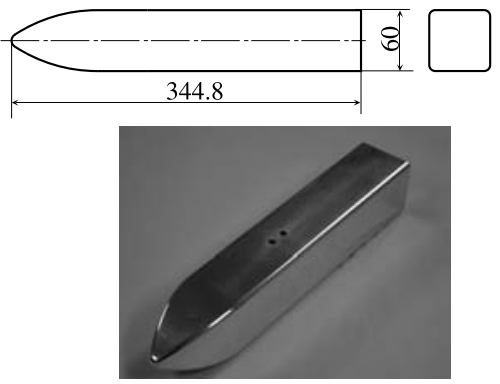

(b) 四角胴体

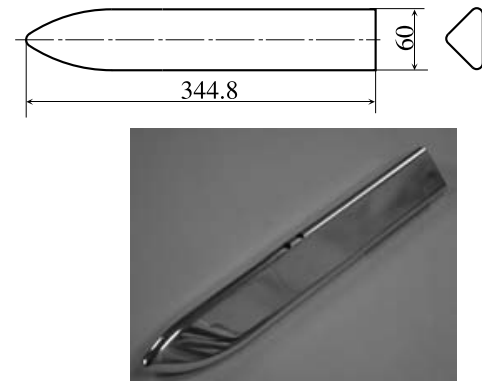

(c) 三角胴体

第 1 図＼cjkstart胴体模型概略図と写真（全長及び水平投影面積が等しい）
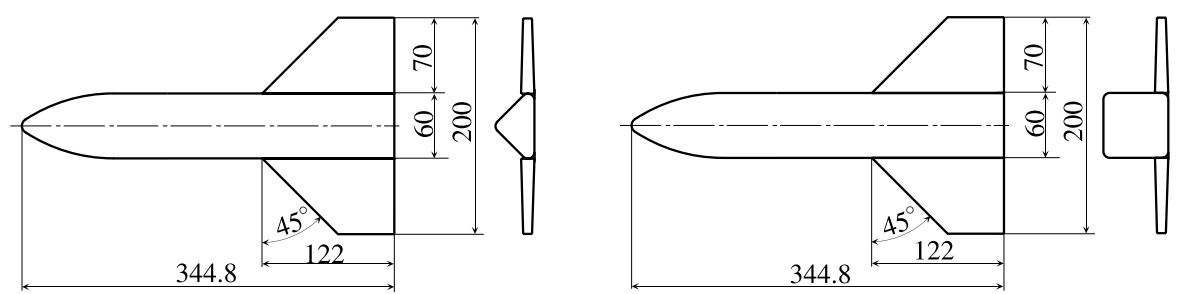

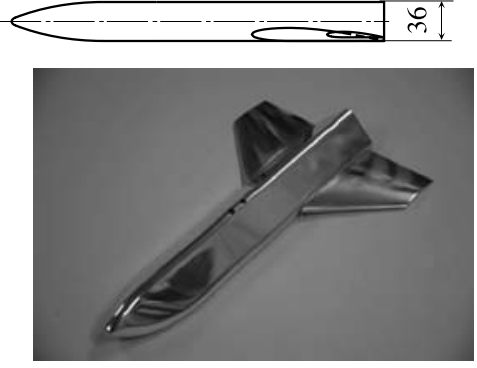

(a) 三角翼胴

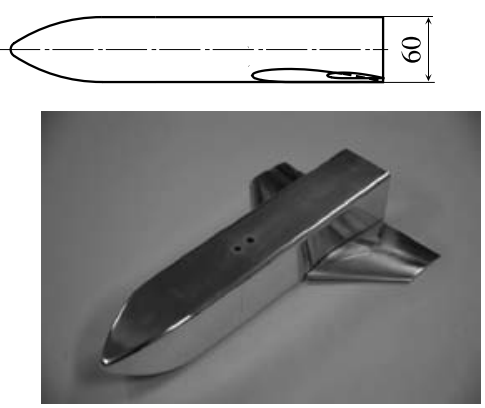

(b) 四角翼胴

第 2 図 翼胴模型概略図と写真 (全長及び水平投影面積が等しい)

第 1 表 実験条件

\begin{tabular}{|c|c|c|}
\hline$M_{\infty}$ & $\alpha$ & $R e$ \\
\hline 0.3 & $-15 \sim 40^{\circ}$ & $3.2 \times 10^{6}$ \\
\hline
\end{tabular}

実的な機体を模擬するために，「四角胴体」，「三角胴体」の 基準断面の角に丸み（丸み半径 $6 \mathrm{~mm}$ ) を持たせてある.

断面形状の異なる 2 種類の翼胴模型を第 2 図に示す . 翼 胴模型の断面形状は四角形，二等辺三角形の 2 種類であり， 胴体のみの模型である「四角胴体」及び「三角胴体」模型

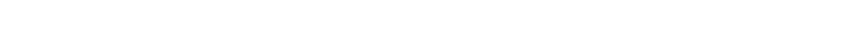
の主翼を用いており，取り外し及び付け替えが可能である． また，主翼は後退角 45 度のシングルデルタ翼形状であり， 翼端は有限の翼弦長を持つ clipped delta 翼となっている . 翼型は NACA0010 翼型を基本形状としたものを用いてい るが , 機体底面をフラットにするために若干の修正を加え ている．なお，主翼に後退角 $45^{\circ}$ のシングルデルタ翼を採 用した理由は, 昨今, 各国で研究されている再使用型宇宙 往還機に後退角 $45^{\circ}$ 程度のシングルデルタ翼を用いたもの か増えてきているためである ${ }^{9213)}$.これらの模型は，すべ て, 全長 $0.3448 \mathrm{~m}$ ，水平投影面積 $3.14 \mathrm{~m}^{2}$ である.これ以 降，断面形状が四角の翼胴模型を「四角翼胴」, 二等辺三角 形の翼胴模型を「三角翼胴」と呼ぶこととする．

2.2 実験方法と実験条件 実験は, 第 1 図及び第 2 図で 示した 3 つの胴体模型及び 2 つの翼胴模型に対して, 空気 力測定及び流れの可視化を行った . 空気力測定の実験条件
を第 1 表に示す.ここで， $M_{\infty}$ は主流マッ八数， $\alpha$ は迎角， Re はレイノルズ数であり，無次元化に用いた代表長は，模 型全長 $(=0.3448 \mathrm{~m})$ である. 流れの可視化は, スモーク ワイヤ法及びオイルフロー法を用いた . なお， スモークワ イヤ法を用いた可視化実験のみ九州大学所有の直径 $2 \mathrm{~m} の$ 円形断面測定部を持つ回流式低速風洞を用いた .

\section{3. 実験結果及び考察}

3.1 空力特性に関する結果と考察 まず, 空力特性につ

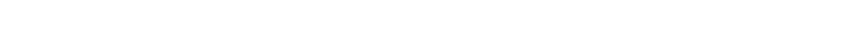
性，揚抗比特性及びピッチングモーメント特性を第 3 図に

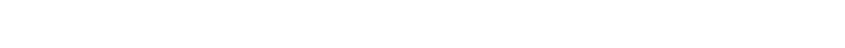
面積 $\left(=3.14 \mathrm{~m}^{2}\right)$ て無次元化している.なお，「真円胴体」， 「三角胴体」及び「四角胴体」の水平投影面積は $1.93 \mathrm{~m}^{2}$ で あるが, 同グラフにおいて翼胴模型と比較をするため, 翼 胴模型の水平投影面積 $3.14 \mathrm{~m}^{2}$ で無次元化を行った . また , ピッチングモーメント特性の基準点は模型先端であり，頭 上げが正である .

第 3 図 (a) に揚力特性を示す．まず，異なる胴体断面形 状を有する 3 つの胴体模型について，「真円胴体」及び「四 角胴体」と比較して，「三角胴体」では揚力係数が大きいこ 


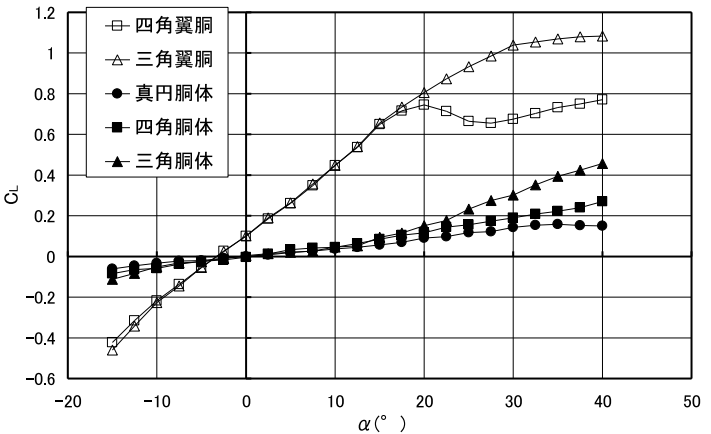

(a) 揚力特性

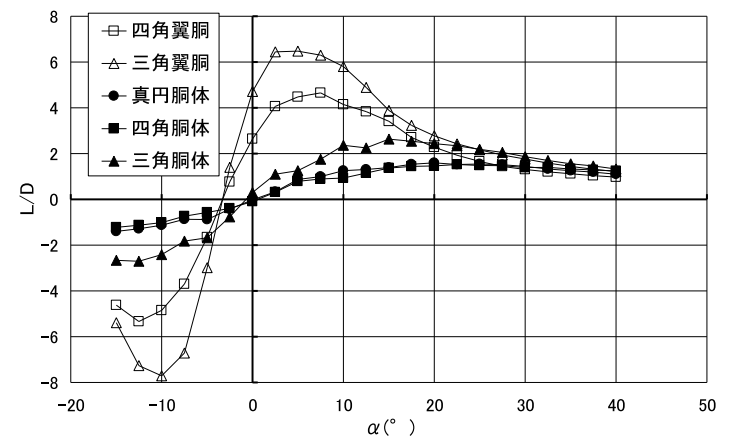

(c) 揚抗比特性

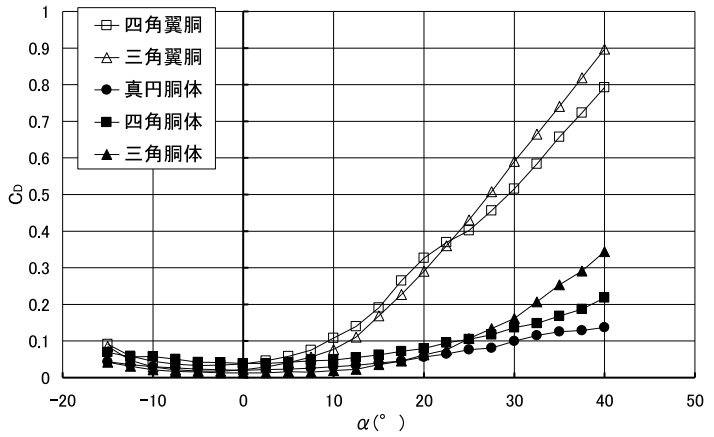

(b) 抗力特性

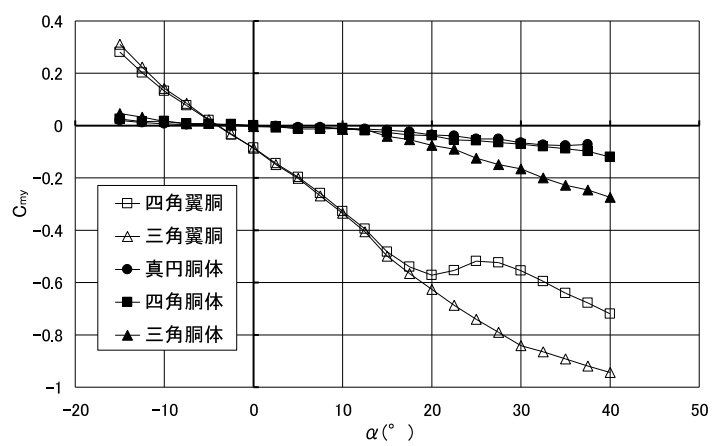

(d) ピッチングモーメント特性

第3図 $M_{\infty}=0.3$ の空力特性

とが分かる. 翼胴模型の場合， $\alpha=20^{\circ}$ 以上の揚力係数が $\ulcorner$ 四角翼胴」と「三角翼胴」で大きく異なり，「四角翼胴」で は明らかに失速しているのに対し，「三角翼胴」では明確な 失速を示さず, 弚の揚力係数は「四角翼胴」と比較して著 しく大きいことが分かる.また, 胴体模型と翼胴模型を比 較すると，高迎角における「三角胴体」と「四角胴体」の 揚力係数の差よりも，「三角翼胴」と「四角翼胴」の差の方 が大きいことか確認できる .これは，「四角翼胴」と比較し て「三角翼胴」は，揚力係数を増加させる効果を有するこ とを示している

第 3 図 (b) に抗力特性を示す. 異なる胴体断面形状を有 する 3 つの胴体模型について，「真円胴体」及び「四角胴 体」と比較して，高迎角時において「三角胴体」では抗力 係数が大きいことが分かる. 「三角胴体」は，第 3 図 (a) の 揚力特性で示されたように，高迎角時において他の 2 つの 胴体模型と比較して，揚力係数が大きい，产のため, 高迎 角時において, 弚の揚力の増加分に相当する抗力か増加し, 他の 2 つの胴体模型より，抗力係数が大きいと考えられる また，低迎角時において，「三角胴体」，「真円胴体」，「四角 胴体」の順に抵抗が大きいことが分かる.これは，主流に対 する模型の前面投影面積の違いによるものだと考えられる

第 3 図 (c) に揚抗比特性を示す. 異なる胴体断面形状を 有する 3 つの胴体模型について, $\alpha=0^{\circ}$ 以降，「真円胴体」 及び「四角胴体」と比較して，「三角胴体」の揚抗比が大き いことが分かる．これは，低迎角時，主流に対する模型の 前面投影面積が「真円胴体」及び「四角胴体」より「三角 胴体」の方が小さく，抗力が小さいためであり，高迎角時 には，弚れに加えて「三角胴体」の揚力係数が大きいため
である、翼胴模型の場合についても同樣な理由により，「四 角翼胴」より「三角翼胴」の揚抗比が大きいと考えられる．

第 3 図 (d) にピッチングモーメント特性を示す.グラフ より, 胴体模型及び翼胴模型共に, 高迎角時において, 三 角の胴体断面を有する模型のピッチングモーメント係数が 大きいことが分かる .

3.2 可視化結果及び考察 前節の空力特性に関する結 果より，高迎角時において，「四角翼胴」より「三角翼胴」 の揚力係数が大きいことが明らかになった .この点につい て考察するためにオイルフロー法及びスモークワイヤ法に よる流れの可視化を行った .

第 4 図及び第 5 図に $\alpha=30^{\circ}$ におけるスモークワイヤ 法による可視化結果を示す.いずれもスリット光を模型側 面に照射し, 模型先端から全長の $75 \%$ 位置断面及び模型後 縁断面の流れ場を模型の下流方向から撮影したものである . 第 4 図は「四角胴体」と「四角翼胴」, 第 5 図は「三角胴 体」と「三角翼胴」の可視化結果である．

第 4 図 (a) より，「四角胴体」において模型上面に前縁剝 離によって生じた縦渦が形成され，後端に向かうにつれて 渦直径が大きくなっていることが分かる.第 4 图 (b) より， $\ulcorner$ 四角翼胴」の胴体上面においても第 4 图 (a) の「四角胴 体」と同樣な縦渦が形成されていることが分かる. 翼上面 の後縁では, ぼんやりとしたスモークが確認され，流れが 淀んでいると推測することができる．

第 5 图では，第 4 図と同樣に「三角胴体」及び「三角翼 胴」のどちらについても前縁剥離によって生じた縦渦が形 成されていることが分かる。しかしながら，第 5 図 (b)よ り「三角翼胴」の模型後縁における流れ場は, 第 4 図と異 


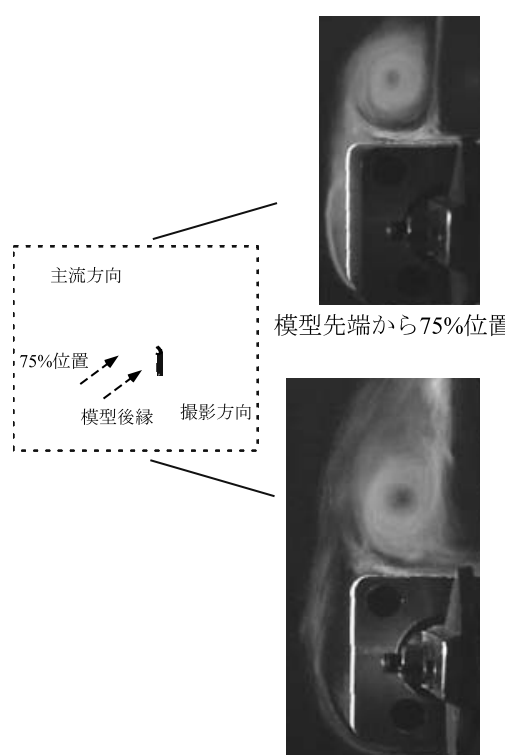

模型後縁

(a) 四角胴体

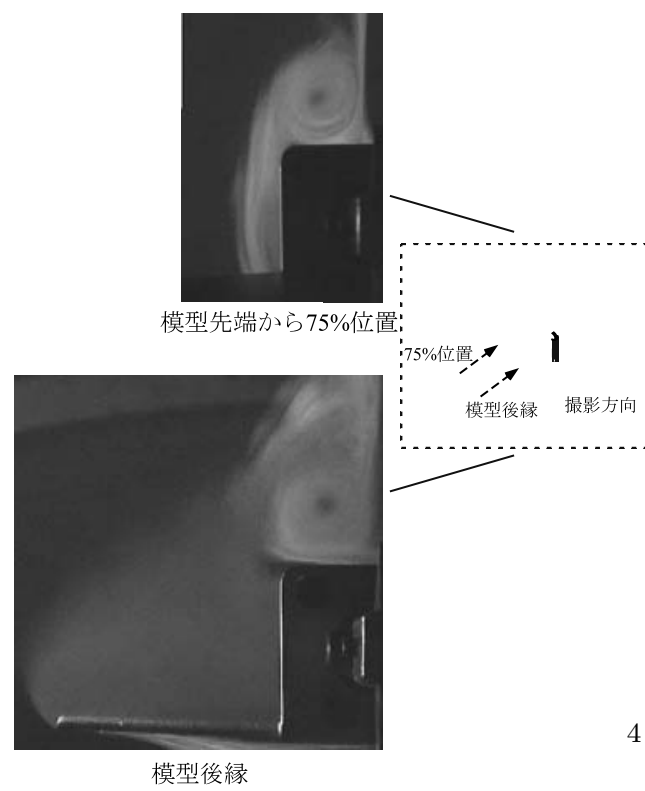

(b) 四角翼胴
第4図 スモークワイヤ法による可視化 結果 $(\ulcorner$ 四角胴体」と「四角翼 胴」, $\left.\alpha=30^{\circ}, U_{\infty}=3 \mathrm{~m} / \mathrm{s}\right)$

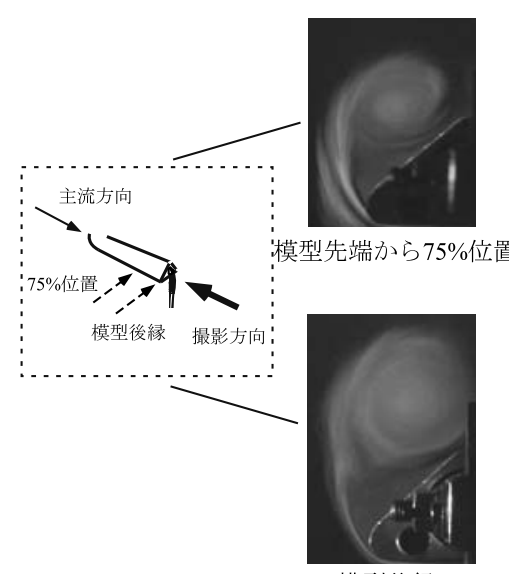

模型後縁

(a) 三角胴体

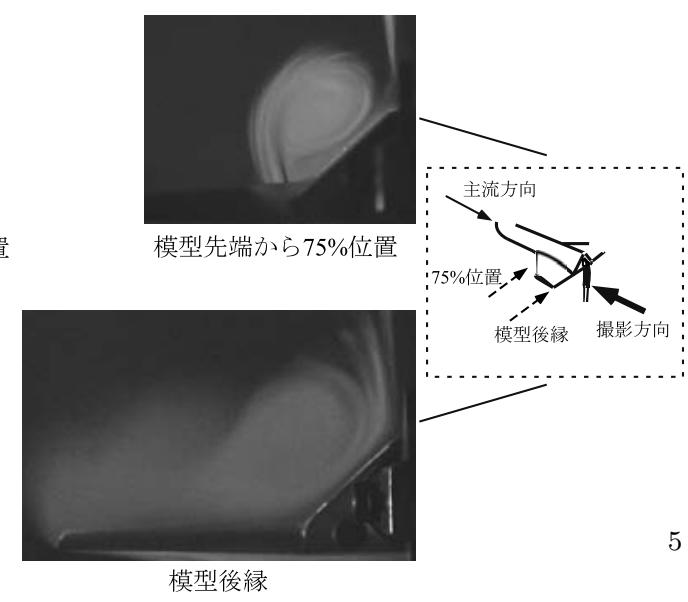

(b) 三角翼胴
第5図 スモークワイヤ法による可視化 結果 (「三角胴体」と「三角翼 胴」, $\left.\alpha=30^{\circ}, U_{\infty}=3 \mathrm{~m} / \mathrm{s}\right)$
なり，胴体で形成された縦渦が翼面上にまで详し，「三角胴 体」で形成された縦渦より大きな縦渦を形成していること か確認できる。

これらのスモークワイヤ法による可視化結果より，まず， 高迎角において「四角翼胴」より「三角翼胴」の揚力係数 が大きいことについて考察する. $\alpha=30^{\circ}$ において，主翼 後退角 $45^{\circ}$ では「四角翼胴」で翼面上に縦渦が生成できな かった 、一方で,「三角翼胴」では, 胴体により発生した縦 渦が, 翼面上にまで達していることか確認できた 。したがっ て, 胴体から発生した前縁剝離渦の影響領域が広がったた め，「四角翼胴」に比べ大きな揚力係数を得ていると考える ことができる .

次に, 翼胴模型において, 胴体断面を三角にした場合の 効果について考察する. Ericsson らは, 翼胴模型では, 翼 のみの模型と比へてて, 前縁剝離渦の崩壞位置がより翼前縁 に移動し，また，崩壤する迎角がより小さくなることを明 らかにしている6,7) . また , 松野らによれば, 後退角 $45^{\circ}$ の

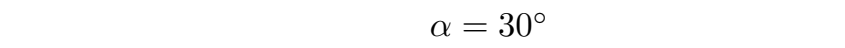
ことが明らかになっている ${ }^{14)}$. 本研究における「四角翼胴」 の場合，松野らの翼のみの結果より小さい迎角で失速を示 しており，Ericsson らの実験結果と同樣に，胴体の影響に より, 崩壊が早まったと推測することができる . しかし, 本 研究における「三角翼胴」の揚力特性は, 胴体から発生した 前縁彔離渦が翼面上にも影響を与えることにより， $\alpha=30^{\circ}$ 以上でも失速を示していない．これらより，翼に胴体を付 加した場合，通常，揚力係数を減少させる方向へ作用する が，胴体を三角断面にすることにより，胴体から発生した 縦渦が翼面上にも影響を与え, 翼のみの模型よりも失速迎 角を大きくし，高迎角域の揚力係数を増加させるという翼 と胴体の干渉効果を有すると考えることができる．

スモークワイヤ法で確認された流れ場をオイルフロー法に よる可視化結果においても確認する.第 6 図に $M_{\infty}=0.3$ における「四角翼胴」及び「三角翼胴」の可視化結果を示す． 第 6 図 (a)より，「四角翼胴」の翼面上ではオイルがた 


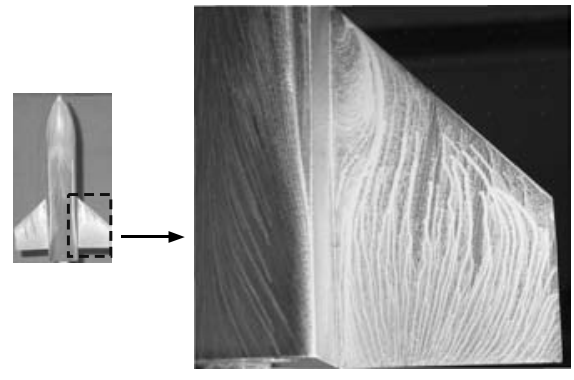

(a) 四角翼胴

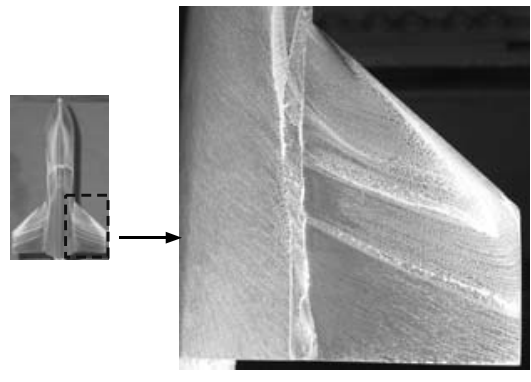

(b) 三角翼胴

第 6 図 オイルフロー法による可視化結果 ( $「$ 四角翼胴」と「三角翼胴」, $\alpha=30^{\circ}, M_{\infty}=0.3$ )

まり太い筋状のフローパターンを示している . また , 翼後 縁に比べ, 翼前縁付近でオイルがたまり筋が太くなってお り, 翼面上で逆流していることが分かる .これらより, 翼面 上の流れは, 翼前縁で剝離し, 失速していると考えること ができる．また，胴体上面におけるフローパターンは翼面 上のパターンと異なっていることが分かる．一方，第 6 图 (b)より，「三角翼胴」の翼面上では, 翼端に向かう流れを 確認でき，胴体における流れと連続的であることが分かる つまり，これらよりスモークワイヤ法による可視化結果に よって確認された「四角翼胴」で翼面上に縦渦が生成され なかったこと，及び，「三角翼胴」における胴体から翼面上 にまで達する前縁剥離によって生じた縦渦の形成が，才イ ルフロー法による可視化結果においても確認することがで きた 。

\section{4. 結論}

本研究では, 異なる胴体断面形状を有する胴体模型及び 翼胴模型を用いて, 亜音速領域における胴体断面形状が空 力特性に及ぼす影響を風洞試験によって実験的に調べた。得 られた結論は以下のとおりである .

1) 胴体模型について, 高迎角時, 「真円胴体」及び「四 角胴体」と比較して，「三角胴体」の揚力係数が大きいこと が確認された .

2) 翼胴模型の場合， $\alpha=20^{\circ}$ 以上において「四角翼胴」 では明らかに失速しているのに対し，「三角翼胴」では明確 な失速を示さず，弚の揚力係数は「四角翼胴」と比較して 著しく大きいことが確認された .

3) 高迎角における「三角胴体」と「四角胴体」の揚力係 数の差よりも，「三角翼胴」と「四角翼胴」の差の方が大き いことが確認できた . 弚のため, 「四角翼胴」と比較して 「三角翼胴」模型は，揚力係数を増加させる効果を有すると 考えられる。

4) 高迎角時に「四角翼胴」より「三角翼胴」の揚力係数 が大きい理由は次のとおりである，迎角 $30^{\circ}$ において，「四 角翼胴」では翼面上に縦渦は生成されず,一方で, 「三角翼 胴」では, 胴体から発生した縦渦が, 翼面上にまで達して いることか確認できた .したがって，胴体から発生した前 縁剝離渦の影響領域が広がったため,「四角翼胴」に比べ大
きな揚力係数を得ていると考えられる．

5) これらにより,空力的に胴体の影響が大きい宇宙往 還機が, 亜音速領域において高迎角での飛行を行う際には, 胴体断面形状を工夫することが空力性能向上に有効である ことが明らかになった .

\section{参 考 文 献}

1) Daniel, D. C., Yechout, T. R. and Zollars, G. J.: Experimental Aerodynamic Characteristics of Missiles with Square Cross Sections, J. Spacecraft Rockets, 19 (1982), pp. 167172.

2) Sigal, A. and Lapidot, E.: Aerodynamic Characteristics of Configurations Having Bodies with Square, Rectangular, and Circular Cross Sections, J. Spacecraft Rockets, 26 (1989), pp. 85-89.

3) Sigal, A.: Aerodynamic Characteristics of Rectangular Cross Sectional Bodies at $M_{\infty}=0.85$, J. Aircraft, 25 (1988), pp. $1018-1022$.

4) Nelson, H. F.: Wing-Body Interference Lift for Supersonic Missiles with Elliptical Cross-Section Fuselages, J. Spacecraft Rockets, 26 (1989), pp. 322-329.

5) Nelson, H. F.: Aerodynamic Forces on Noncircular CrossSection Missile Forebodies, J. Aircraft, 29 (1992), pp. 612618.

6) Ericsson, L. E.: Effect of Fuselage Geometry on Delta-Wing Vortex Breakdown, J. Aircraft, 35 (1998), pp. 898-904.

7) Straka, W. A. and Hemsch, M. J.: Effect of a Fuselage on Delta Wing Vortex Breakdown, J. Aircraft, 31 (1994), pp. 1002-1005.

8) Hall, R. M.: Influence of Forebody Cross-Sectional Shape on Wing Vortex-Burst Location, J. Aircraft, 24 (1987), pp. 645-652.

9) Sippel, M., Klevanski, J., Burkhardt, H., Eggers, T., Bozic, O., Langholf, P. and Rittweger, A.: Progress in the Design of a Reusable Launch Vehicle Stage, AIAA Paper 2002-5220, 2002.

10) Spies, J.: RLV Hopper: Consolidated System Concept, IAC02-V.4.02, 2002.

11) Wallace, J., Olds, J., Charania, A. C. and Woodcock, G.: A Study of Arts: A Dual-Fuel Reusable Launch Vehicle with Launch Assist, AIAA Paper 2003-5269, 2003.

12) Jategaonkar, R., Behr, R., Gockel, W. and Zorn, C.: Data Analysis of Phoenix RLV Demonstrator Flight Test, AIAA Paper 2005-6129, 2005.

13) Brown, F. N. and Olds, R. J.: Evaluation of Multidisciplinary Optimization (MDO) Techniques Applied to a Reusable Launch Vehicle, AIAA Paper 2005-707, 2005.

14）松野 隆, 横内 滋, 中村佳朗 : 前縁フラップによる $45^{\circ}$ デル 夕翼のロール制御, 日本航空宇宙学会論文集, 52 (2004), pp. 429-434. 